\title{
A Study on the Cultivation and Development of the Sixth Industry in Jingzhou
}

\author{
Qibing FAN, Hong WEI, Yajun ZENG \\ Yangtze University, Jingzhou, China \\ 378300891 @qq.com, weihong0728@126.com \\ zyajun@yangtzeu.edu.cn
}

\begin{abstract}
Jingzhou is a big agricultural city with abundant agricultural resources. In recent years, the development of agriculture there has entered a new stage and is heading to mass production, diversification and precision. However, the rural economy is facing some challenges, such as feminization and aging of labor force, and the insufficiency of development vitality. The sixth industry is a new way to solve the above problems. As to the development of the sixth industry in Jingzhou, the article introduces the present situation, analyzes the related problems, and then puts forward some feasible suggestions. To begin with, the government and the relevant departments should come up with the development outline and support policies for the sixth industry. What's more, they should focus on strengthening the cultivation of new type of agricultural business entities and innovating more paths to develop modern agriculture. Last but not least, the relevant industrial supporting platforms should be constructed in order to help out the development of the sixth industry.
\end{abstract}

Keywords: Jingzhou, Agriculture, The Sixth Industry, Industrial Convergence

\section{Introduction}

The concept of the sixth industry was first proposed by the Japanese scholar Imamura Naraomi in 1990s for solving dilemma faced by Japanese agriculture. In his opinion, the sixth industry is the projects and activities that creating job opportunities especially for elder people and women to increase agricultural income by combining secondary industry and tertiary industry with primary industry [8]. He advocated farmers to engage in a variety of operations, that is, they not only grew crops (primary industry), but also engaged in the processing of agricultural products Industry (secondary industry) and sales of agricultural products (tertiary industry), so that they could obtain more added value. Since $1+2+3$ or $1 \times 2 \times 3$ are both equal to 6 , it is called the sixth industry [3].

Professor Zhang Laiwu, Chinese former vice minister of Ministry of Science and Technology, and some Chinese scholars further developed the theoretical system. They thought of the sixth industry as the highest form of the industrial structure, and its core is to develop primary, secondary and tertiary industry and integrate internet 
and cultural and creative industry. The real goal is to realize the increase of agricultural added value and farmers' income [10].

Jingzhou is a big agricultural city and known as "land of fish and rice, China granary". In recent years, the rural areas there, however, are facing the challenge of massive labor transfer as well as feminization and aging of labor force. Agriculture is becoming sideline and urban-rural income gap is expanding which reflect the dilemma that rural economy is suffering from the insufficiency of development vitality [6]. In the No.1 Central Document and on the Central Rural Work Conference in China in 2017, such modern industrial organization modes as industry chain and value chain are introduced into agriculture to promote the integration of the primary, secondary and tertiary industry. As a new light spot and form of current agricultural development, the sixth industry is the development of modern agriculture as an excellent remedy for this situation [4] in Jingzhou.

\section{The Present Situation of the Sixth Industry in Jingzhou}

\subsection{Obvious Advantages but Slow Growth in Agricultural Production}

As shown in Table 1, from the view of the proportion of agriculture in the primary industry of Jingzhou from 2013 to 2016, agricultural production has obvious advantages and accounts for more than $35 \%$ of primary industry each year; as for cumulative growth rate, the agricultural growth rate is the slowest; the added value of agriculture from 2013 to 2016 is 15.78 billion yuan, and the cumulative growth rate is $29.50 \%$, which is lower than that of forestry and fisheries. At the same time, it can be seen from Table 2 that the average annual growth rate of agricultural output value is the lowest of $1.59 \%$, which is much lower than $6.21 \%$ of the average annual growth rate in primary industry output value from 2013 to 2016.

Table 1. The Output Value of Primary Industry in Jingzhou in 2013-2016 (unit: 100 million yuan, $\%)$.

\begin{tabular}{|c|c|c|c|c|c|}
\hline Item & 2013 & 2014 & 2015 & 2016 & $\begin{array}{l}\text { Cumulative } \\
\text { Growth Rate }\end{array}$ \\
\hline Output value of Primary industry & 578.34 & 616.16 & 631.45 & 692.78 & 29.50 \\
\hline Output value of agriculture & 253.1 & 262.74 & 257.99 & 260.14 & 7.84 \\
\hline Output value of forestry & 6.48 & 7.02 & 7.77 & 8.38 & 44.23 \\
\hline Output value of animal husbandry & 138.58 & 142.4 & 134.58 & 153.02 & 16.79 \\
\hline Output value of fishery & 173.2 & 196.18 & 209.4 & 237.95 & 57.99 \\
\hline $\begin{array}{l}\text { Proportion of agriculture in primary } \\
\text { industry }\end{array}$ & 43.76 & 42.64 & 40.86 & 37.55 & \\
\hline Proportion of agriculture in forestry & 1.12 & 1.14 & 1.23 & 1.21 & \\
\hline $\begin{array}{l}\text { Proportion of agriculture in animal } \\
\text { husbandry }\end{array}$ & 23.96 & 23.11 & 21.31 & 22.09 & \\
\hline
\end{tabular}


Proportion of agriculture in fishery $\quad 29.95 \quad 31.84 \quad 33.16 \quad 34.35$

Notes: the above data are derived from Jingzhou Statistical Yearbook from 2013-2016 and Statistical Yearbook from 2013-2017 of Hubei Province.

Table 2. The Growth Rate of Primary Industry of Jingzhou in 2013-2016 (unit: \%).

\begin{tabular}{llllll}
\hline Item & 2013 & 2014 & 2015 & 2016 & Average \\
\hline Agriculture & 4.92 & 2.4 & -1.81 & 0.83 & 1.59 \\
Forestry & 11.53 & 1.5 & 10.68 & 0.79 & 6.13 \\
Animal husbandry & 5.77 & 4 & -5.49 & 13.70 & 4.50 \\
Fishery & 14.5 & 7.8 & 6.74 & 13.63 & 10.67 \\
Primary industry & 8.11 & 4.5 & 2.5 & 9.71 & 6.21 \\
\hline
\end{tabular}

Notes: the above data are derived from Jingzhou Statistical Yearbook from 2013-2016 and Statistical Yearbook from 2013-2017 of Hubei Province.

\subsection{Steady but Slow Growth of Agricultural Product Processing Industry}

In recent years, seven industrial systems for agricultural product processing in Jingzhou have been set up, which involve in high-quality grain, cotton, oil, fruits and vegetables, livestock and poultry, aquatic products and paper products. The number of enterprises above designed size reached 542 in 2016, whose output value was 134.61 billion yuan and rose by $9.13 \%$ year-on-year. As shown in Table 3 , the proportion of agricultural product processing industry in the secondary industry had been more than $25 \%$ in 2012-2015, and it even accounted for almost 30\% in 2014. Meanwhile, from 2012 to 2014, the production value of agricultural product processing industry increased from 43.97 billion yuan to 64.3 billion yuan, and the cumulative growth rate was $46.25 \%$, while the output value and growth in 2015 were slightly dropped down, specifically, the output value is 62.01 billion yuan with a drop of $3.51 \%$ year-on-year.

Table 3. The Growth Rate of the Second Industry of Jingzhou in 2013-2015 (unit:100 million, $\%)$.

\begin{tabular}{|c|c|c|c|c|}
\hline Item & 2012 & 2013 & 2014 & 2015 \\
\hline Output of the second industry & 1519.88 & 1896.66 & 2183.5 & 2362.94 \\
\hline $\begin{array}{l}\text { Agricultural product processing } \\
\text { industry }\end{array}$ & 439.69 & 541.57 & 643.04 & 620.45 \\
\hline $\begin{array}{l}\text { Proportion of agricultural } \\
\text { Product processing industry in } \\
\text { the second industry }\end{array}$ & 28.93 & 28.55 & 29.45 & 26.26 \\
\hline $\begin{array}{l}\text { Growth rate of agricultural } \\
\text { Product processing industry }\end{array}$ & 17.25 & 23.17 & 18.74 & -3.51 \\
\hline
\end{tabular}


Notes: the above data are derived from Jingzhou Statistical Yearbook from 2013-2016. The related data of 2016 have not been issued publicly.

\subsection{Relatively Backward but Promising in Rural Service Industry}

As can be seen from the Figure 1, there is an obvious increasing trend in the added value of services on agriculture, forestry, animal husbandry and fishery from 2012 to 2015. Specifically, it has increased cumulatively by 811 million yuan or by $247.26 \%$; while the added value of accommodation and catering industry are in a light of amplitude fluctuation state, and their cumulative growth were respectively 54 million yuan and 400 million yuan, that is to say, the cumulative growth rate were $6.89 \%$ and 13.23\% respectively; in addition, from 2013 to 2015, the average annual growth rate on accommodation, catering industry and agriculture, forestry and the added value of service industry on agriculture, forestry, animal husbandry and fishery were $2.51 \%$, $4.54 \%$, and $67.55 \%$.

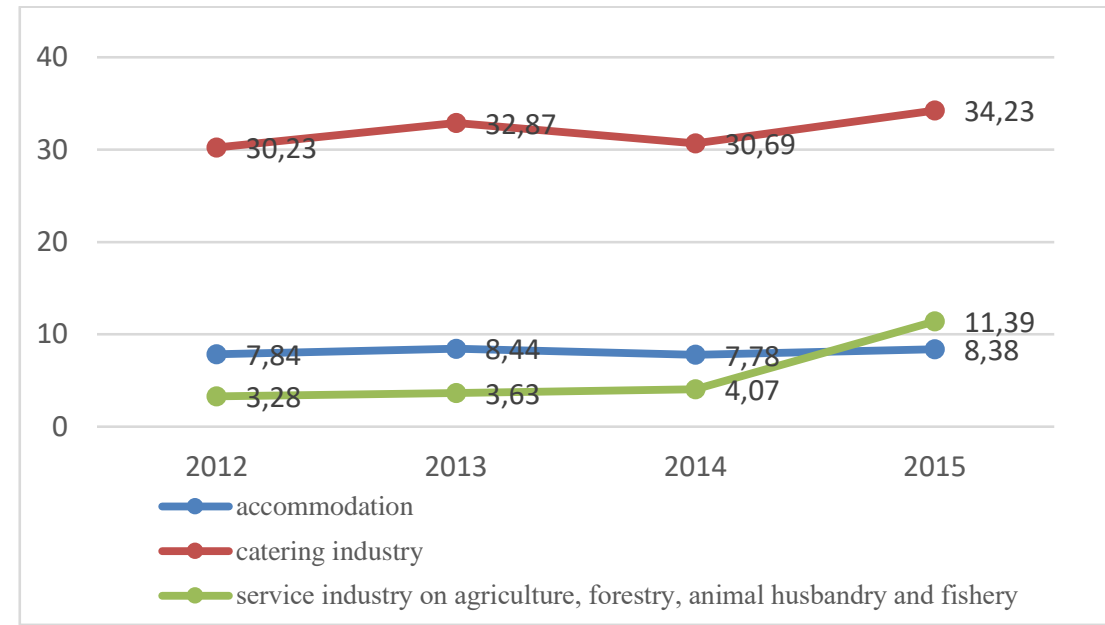

Notes: the above data are derived from Jingzhou Statistical Yearbook from 2013-2016. The related data of 2016 have not been issued publicly. 
Fig. 1. The Added Value of Accommodation, Catering Industry and Services on Agriculture, Forestry, Animal Husbandry and Fishery in Jingzhou in 2013-2016 (unit:100 million yuan).

\section{The Main Problems Faced by Jingzhou in Cultivating and Developing the Sixth Industry}

\subsection{Lack of Adequate Knowledge about the Sixth Industry}

To learn about how much the citizens, know about the sixth industry, we make investigation through questionnaires and face-to-face interviews in Jingzhou. According to the survey, about $80 \%$ of the villagers, $50 \%$ of the village cadres and $30 \%$ of the township cadres have never heard of the concept of the sixth industry, and only $20 \%$ of people think that the industry may be associated with industrial convergence. In response to the willingness to develop the sixth industry, villagers' enthusiasm is not high, many agricultural cadres do not know how to start, and some of them take the sixth industry as "targeted poverty alleviation in China", which is developed essentially depending on financial support. Therefore, the public have some error perception of the sixth industry, and it is a long way to go for cultivating and developing the sixth industry.

\subsection{Talent Shortage in the Sixth Industry}

As the rural migrant workers increase year by year, rural area faces a serious lack of labor force. In recent years, although some migrant workers return home, the growth rate of labor and talented person still cannot keep pace with the sixth industry's rapid development, in addition, there is a much more serious shortage in some kinds of agricultural professional and technical personnel. The existing structure of scientific and technological personnel is aging and thus lacking in passion and innovation, which becomes an obstacle to the further development of the sixth industry.

\subsection{Insufficient Construction Funds and Obstructed Financing Channels}

To develop the sixth industry, it needs a long cycle and relatively huge construction funds which is difficult to raise simply by a single investment subject. As a result, the new operators tend to face the plight of capital shortage, especially in seasonal funds [7]. There is usually a relatively high, complex program, limited loan amount in commercial loan, which lead to the obstructed financing channel. In addition, in the process of cooperation and development, due to lack of trust in partners, investors resist to invest much capital to the operators. Without the sufficient funds, it is difficult for the operators to carry out advanced agricultural technology, collect rich 
information and increase the scale of the industry, which severely restrict the development of the sixth industry in Jingzhou.

\subsection{Lagged Brand Building}

Brand building is of great significance to enhance the added value of agricultural products. Nowadays, the characteristic agriculture product superiority in Jingzhou has not been transformed as the scale superiority and benefit superiority, the main reason of which lies in the lagged brand building. Firstly, brand cultivation and protection systems have not been established. Brand development is lack of unified, systematic planning, organization and guidance. Secondly, brand influence is urgently needed to expand. Most of the brand influence only stay in the local area, which lead to the lower social trust degree. The agricultural brand status in Jingzhou is not commensurate with the status of the big agricultural city. Thirdly, the concept of regional public brand needs to be popularized. The construction of regional public brand has not been planned as a whole, the brand resources have not been well integrated, and the public brand system has not yet been established.

\section{$4 \quad$ Policy Recommendation on Cultivating and Developing the Sixth Industry in Jingzhou}

As early as 20 years ago, Japan and Korea began the exploration and practice in the sixth industry, and have accumulated more abundant experience. In recent years, many provinces and cities in China also actively take part in the practice of sixth industry, so far, such places have gained some successful experience as the Jinshan District of Shanghai, Yangling Agricultural High-tech Industry Demonstration Zone of Shanxi Province, Fuyang of Zhejiang Province, Nantong of Jiangsu Province and Guangdong Province, etc. Learning from successful practical experience at home and abroad, it is undoubtedly important to cultivate and develop the sixth industry in Jingzhou.

\subsection{Overall Planning on the Development Outline and Support Policies for the Sixth Industry}

The development of the sixth industry is inseparable from the support of the policy, so the primary task is to do a comprehensive planning, which is also the successful experience of Japan, South Korea and Jinshan District of Shanghai, etc. In reference to their experience, the government of Jingzhou can put forward the strategic measures and work out the formulation on Jingzhou Development Outline for the Sixth Industry, and then guide the counties to develop the corresponding action plan, so as to form consensus and resultant force of developing the sixth industry in the whole city. This outline should be drawn up considering the industrial base, location characteristics, resource advantages and cultural endowments of Jingzhou [2]. More 
importantly, it should clearly set the development goals and overall task, and focus on the ecological industrial integration, so that we will develop the sixth industry with scale, Standardization, quality, commercialization and specialization. Meanwhile, the government should also adopt the following policies to support the development of the six industry:

Preferential Policy to the Base Construction of the Sixth Industry on Rural Construction Land. Priority should be given to those who need non-agricultural construction land to set up enterprises of agricultural products processing, and declaration and use of land in the abandoned schools, four kind of wasteland shall be inclined to the sixth industry.

Funding Support Policy. Financial institutions should study and formulate the credit policy to support for the development of the sixth industry. For the sixth industrial business entities with large-scale, strong leading role, high credit ratings, the banks should implement preferential policies such as loan priority, interest rate concessions, easing and simplifying procedures. The local agricultural sectors, finance offices, banking regulatory bureau should study specific policies to support financial institutions for the sixth industry to carry out mortgage loan business towards orders for agriculture, agricultural production facilities, agricultural machine, land contract and management rights, forest ownership, right to use water and beach. Guarantee institutions should study and formulate access conditions, put the eligible sixth industrial entities into the scope of loan guarantee services, and give priority to guarantee services [1]. In addition, policies should also be formulated to attract social capital to participate in the development of the sixth industry.

Setting Up Financial Subsidy Projects for the Sixth Industry. Following the experience of Japan and Korea, the government and the relevant departments should put into more fund to carry out fiscal subsidies for the sixth industry, establish specialized accreditation agencies, standardize certification process, which can be considered as the basis that provide precise assistance and the sixth industry business owners obtain financial subsidies [9]. As a result, it can improve the implementation effect of government subsidy policy.

\subsection{Strengthening the Cultivation of New Type of Agricultural Business Entities}

The shortage of talent resources is the bottleneck problem of the current development of the sixth industry in Jingzhou, so it is necessary to cultivate new type of agricultural business entities to improve staff quality, including cultivating leading specialized households, family farm as the backbone, making professional cooperatives and leading enterprises as the link.

Speeding Up the Cultivation of New Type of Professional Farmers. The authorities should try every means to broaden training channels and forms to carry out vocational education training, expand the scale of sunshine projects and rural practical personnel training, conduct a wide range of training on large grain farming, large breeding families, family farm operators, leaders of cooperatives and so on. Furthermore, the government and the relevant departments should study and 
formulate the identification standard of professional farmers as the basis of cultivation and support.

Vigorously Developing Specialized Households and Family Farms. The government and the relevant departments should explore identification standards towards specialized households and family farms of different production areas. The new added agricultural subsidies will be tilted to those identified specialized households and family farms, and the contracted land transfer should also be encouraged and supported for them.

Accelerating the Development of Farmer's Cooperatives. The government and the relevant departments should encourage farmers to set up diversified and multitype cooperatives, such as professional cooperation and joint-stock cooperation. At the same time, they should establish the evaluation mechanism of model cooperatives to publish a list of model cooperatives at different levels, and take them as the key supportive subjects.

Strengthening the Leading Enterprises of Agricultural Industrialization. The government and the relevant departments actively promote the leading enterprises to cooperate with farmers and cooperatives, and take the road of win-win development between agricultural enterprises and farmers and cooperatives.

\subsection{Innovating more Paths to Develop Modern Agriculture}

Jingzhou should focus on the development of modern agriculture, aim at developing brand agriculture, leisure agriculture, ecological agriculture and building the sixth industry as the goal, take "Internet+", "cultural creativity+" as the means. Through adjusting the industrial structure of agriculture and innovating the way of agricultural development, we can improve the level of agricultural modernization and increase farmers' income.

Carrying Out Agricultural Brand Strategy Deeply. Firstly, "Jing Chu taste" regional agricultural products can be chosen as the core public brand to excavate and protect special agricultural products, so as to form the leading and dominant industrial structure of "high quality rice, green vegetables, famous fruits and special breeding", "one village with one industry" and "one village with one product". It is essential for the operators to improve the agricultural quality, brand and taste. Secondly, the operators should further strengthen the brand integration, gradually improve standardized cultivation techniques of brand agricultural products, and formulate the operation procedures, technical standards and product packaging standards of representative agricultural brands. Thirdly, the external image of the products and brands should be carefully dealt with, which can enhance the intrinsic value of product brands.

Developing Leisure Agriculture, Ecological Agriculture and Promoting the Integration of Rural Tourism in the Whole Region. Firstly, combined with the sixth industry, the government should actively promote the integration of agriculture, forestry and tourism, culture, health and other industries, and strive to build pastoral complex, so as to form the new highlight and new format on agricultural industry development of "eco-oriented, industry-based and cultural landscape". Secondly, 
combined with the characteristics of Jingzhou, the government should vigorously build the Chu Culture leisure tourism industry belt, the red leisure tourism industry belt, the pastoral scenery leisure tourism industry belt, the green development leisure tourism industry zone, the eco-tourism leisure tourism industry and other agricultural tourism agglomeration area construction. Thirdly, combined with agricultural and special resources, organize a series of agricultural festivals, such as grape festival, peach blossom festival, strawberry festival, peach festival, crayfish festival and so on. Through deeply seeking organic integration of traditional culture and modern elements, the operators can guide the development of farming and fishing culture, promote the integration of agriculture and cultural creativity, science and technology development, design services, ecological construction, landscape tourism, and build leisure agriculture park combined with agriculture sightseeing, farming experience, education exhibition and cultural heritage.

\subsection{Strengthening the Construction of Industrial Support Platform to Help out the Development of Sixth Industry}

The development of the sixth industry cannot do without the support of platform construction. The support system helps the integrated operation and management of the entire process including production, processing, distribution, export, experience, tourism, sales and consumer [5]. Therefore, Jingzhou should strengthen the construction of platform to promote the development of the sixth industry.

Strengthening the Construction of Research Platform and Think Tank. The government should give full play to the intellectual advantages of Yangtze University and the agricultural scientific research institutes, and encourage scientific research personnel to go to the forefront of the industry, agricultural products processing enterprises to carry out product research and technical guidance. At the same time, the government should carry out the think tank construction plan, and construct highlevel think tank for scientific and technological innovation and enterprise business.

Building Diversified Industrial Development Platforms. The network operators can be introduced to build product sales platform. The authorities can lay down some favorable policies to attract social forces to build the sixth industry incubation platform, scientific and technological achievements transformation platform, brand planning and creative platform, etc.

Building Innovation and Entrepreneurship Platform. In order to provide talents support for industrial development, the government should actively guide and encourage young intellectuals, university students, returning migrant workers to join the development of the sixth industry in Jingzhou.

\section{Conclusion}

The sixth industry is a bright spot and a new pattern of the current agricultural development. It is of great practical significance to cultivate and develop the sixth industry for Jingzhou to change the mode of agricultural development and promote 
the modernization of agriculture. Developing the sixth industry can effectively stimulate the vitality of agriculture, promote the development of local industries and new industries, and enhance the driving force of rural economic development. From the perspective of reciprocity benefit and industry complementarities, the sixth industry is an important starting point to accelerate the modernization of agriculture. From the perspective of the continuous increase of basic requirements for quality of life, the sixth industry is an effective way to expand the multi-function of agriculture. From the realistic challenge of coping with the hard constraints of resource environment, the sixth industry is the objective requirement of sustainable development of agriculture.

From the gradual change of farmers' income, the sixth industry is the inevitable choice to build a moderately prosperous society in all respects. Learning from the successful practical experience at home and abroad, based on the actual situation in Jingzhou, the government and the relevant departments should overall plan on the development outline and support policies for the sixth industry. What's more, they should focus on strengthening the cultivation of the new type of agricultural business entities and innovating more paths to develop modern agriculture. Last but not least, the relevant industrial supporting platforms should be constructed in order to help out the development of the sixth industry.

\section{References}

1. Cheng, C., Xie, X.: The Main Practice and Enlightenment of Developing the Sixth Industry in Japan and Korea[J] (in Chinese). Economic Review, 2016(08): 114-118.

2. Cheng, P.: Practice and Effect of Developing the Sixth Industry in Jinshan District[J] (in Chinese). Shanghai Rural Economy, 2016(3): 16-18.

3. Imamura Naraomi. Sixth industrialization for aquiculture to create additional values[M] (in Japanese). The 21st Century Village Planning, 1998: 1-28.

4. Jin, Y., Luo, Z., Hu, S.: et al. Development of the "Sixth Industry" and its support by chemical technology[J]. Chemical Industry and Engineering Progress, 2017(4): 01.

5. Kim, H. G., Sivamani, S., Lee, M. et al.: A Study on Integrated Support Platform for Sixth Industrialization of Agriculture[J]. Advanced Science Letters, 2016, 22(9): 2358-2362.

6. Kong, X, Zhou, Z.: Developing the Sixth Industry: Practical Significance and Policy Choices[J]. Review of Economy and Management, 2015(01): 14.

7. Lu, Z.: The Sixth Industry: Japan's Practice and Reference Significance[J] (in Chinese). Contemporary Econmoy of Japan, 2016(04).

8. Nakano, K.: The Sixth Industrialization for Japanese Agricultural Development[J]. The Ritsumeikan economic review: the bi-monthky journal of Ritsumeikan University, 2014, 63(3): 314-326.

9. Wu, J., Zhao, B.: Comparative Study on the Development of the Sixth Industry in Japan and Korea[J](in Chinese).Journal of Commercial Economics, 2016(18): 127-129.

10. Zhang, L.: Innovation and Entrepreneurship Guided by the Theory of the Sixth Industry[J] (in Chinese). China Soft Science, 2016(01): 1-5. 